\title{
Erratum to: Evaluating Perceived Quality through Sensory Evaluation in the Development Process of New Products: A Case Study of Luxury Market
}

Cédric Avanzini, Fabrice Mantelet, Améziane Aoussat, Fabrice Jeanningros, and Carole Bouchard

Erratum to:

Chapter "Evaluating Perceived Quality through Sensory Evaluation in the Development Process of New Products: A Case Study of Luxury Market" in: A. M. Lokman et al. (Eds.): Proceedings of the 7th International Conference on Kansei Engineering and Emotion Research 2018, AISC 739, https://doi.org/10.1007/978-981-10-8612-0_40

In the original version of the book, the following corrections have been incorporated in chapter "Evaluating Perceived Quality through Sensory Evaluation in the Development Process of New Products: A Case Study of Luxury Market":

Affiliations of first and fourth authors have been updated.

Figures 1, 2 and 5 have been updated with new images.

Caption of Fig. 4 has been corrected.

The erratum chapter and the book have been updated with the changes.

The updated online version of this chapter can be found at https://doi.org/10.1007/978-981-10-8612-0_40 